\title{
Híbridos de Sorgo (Sorghum bicolor (L.) Moench) Cultivados sob Níveis Crescentes de Adubação. Rendimento, Proteína Bruta e Digestibilidade in Vitro ${ }^{1}$
}

\section{Miguel Marques Gontijo Neto ${ }^{2}$, José Antônio Obeid ${ }^{3}$, Odilon Gomes Pereira ${ }^{3}$, Paulo Roberto Cecon ${ }^{4}$, Magno José Duarte Cândido ${ }^{5}$, Lídia Ferreira Miranda ${ }^{6}$}

\begin{abstract}
RESUMO - Objetivou-se com este trabalho avaliar o rendimento forrageiro, os teores de proteína bruta (PB) e a digestibilidade in vitro de matéria seca (DIVMS) de cinco híbridos de sorgo forrageiro(AG-2002, AG-2005E, AG-X202, AG-X213 e AG-X215), cultivados sob quatro níveis de adubação NPK. Utilizou-se o delineamento em blocos casualizados, em um esquema fatorial 5 x 4 com quatro repetições. Os híbridos avaliados apresentaram altas produções médias de MS/ ha e resposta linear positiva, em função da adubação, ressalvando a alta produtividade (15,47 t/ha) nas parcelas sem adubação, em função da fertilidade do solo e das condições climáticas. Os híbridos apresentaram respostas diferenciadas quanto aos teores de PB, em função da adubação, predominando respostas quadráticas, determinando o comportamento quadrático da produção de proteína bruta. A DIVMS e a produção de matéria seca digestiva apresentaram respostas lineares positivas em função da adubação, sendo a produção de matéria seca digestível fortemente correlacionada $(0,91 * *) \operatorname{com}$ o aumento da produção de MS/ha.
\end{abstract}

Palavras-chave: sorgo forrageiro, forragem, adubação, rendimento

\section{Sorghum (Sorghum bicolor (L.) Moench) Hybrids Cultivated under Increasing Fertilization Levels. Yield, Crude Protein and in Vitro Digestibility}

\begin{abstract}
The objective of this research was to evaluate the forage yield, crude protein (CP) contents and dry matter (DM) in vitro digestibility of five forage sorghum hybrids (AG-2002, AG-2005E, AG-X202, AG-X213 e AG-X215), cultivated under four NPK fertilization levels. A randomized blocks design, in a $5 \times 4$ factorial scheme, with four replicates, was used. The evaluated hybrids showed high average DM/ha yield and positive linear answer in function of fertilization, except for the high productivity (15.47 t/ha) in the plots without fertilization, in function of soil fertilization and climatic conditions. The hybrids showed different answers for the CP contents, according to the fertilization, in a quadratic way, determining the quadratic behavior for the crude protein yield. IVDMD and digestive dry matter yield showed positive linear answers in function of fertilization, and the digestible dry matter yield was highly correlated $\left(0.91^{* *}\right)$ with the increase of $\mathrm{DM} /$ ha yield.
\end{abstract}

Key Words: forage sorghum, forage, fertilization, yield

\section{Introdução}

A estacionalidade de produção das forrageiras nos trópicos e a necessidade de se obter maior uniformidade na produção de leite durante o ano, bem como de atender a produção intensiva de carne bovina, têm levado os pecuaristas a adotarem práticas de conservação de forragens, principalmente na forma de silagem. É grande o número de plantas forrageiras, anuais e perenes, que podem ser utilizadas para a produção de silagem. O milho (Zea mays, L.) e o sorgo (Sorghum bicolor (L.) Moench.) têm sido apresentados como as espécies mais adaptadas ao processo de ensilagem pela facilidade de cultivo (Valente,1992), pelos altos rendimentos por hectare (Cummins, 1981; Pereira et al., 1993) e pela qualidade da silagem produzida, sem a necessidade de aditivos para estimular a fermentação (Zago, 1991).

Na maioria dos trabalhos conduzidos com sorgo, a tônica tem sido estudar as competições entre cultivares, observando-se grande amplitude na produção de matéria seca. Uma boa confirmação desta afirmativa pode ser observada no trabalho de Corrêa et al. (1996), que, em um estudo comparativo entre 13 híbridos de sorgo, encontraram produção de matéria natural $(\mathrm{MN})$ variando de 12,0 a 44,67 t/ha e produ-

\footnotetext{
${ }_{1}$ Parte da tese de mestrado do primeiro autor.

${ }_{2}^{2}$ Pesquisador Embrapa Gado de Corte, CP 154, 79002-970, Campo Grande-MS. E.mail: mgontijo@cnpgc.embrapa.br

3 Professor Depto. de Zootecnia/UFV. Av. P. H. Rolfs, s/n, 36.571-000, Viçosa-MG. E.mail: jaobeid@ufv.br; odilon@ufv.br

${ }^{4}$ Professor Depto. de Informática/UFV. E.mail: cecon@dpi.ufv.br

${ }^{5}$ Doutorando em Zootecnia/UFV. Av. P. H. Rolfs, s/n, 36.571-000, Viçosa-MG. E.mail: magno@alunos.ufv.br

${ }^{6}$ Professora FEAD-MG. E.mail: lidia.miranda@fead.br
} 
ção de matéria seca (MS) de 4,14 a 14,77 t/ha, sendo os maiores valores relativos aos híbridos de maior altura. Valente et al. (1984), avaliando quatro variedades de sorgo, para silagem, obtiveram produção de MS de 12,4 a 26,2 t/ha.

Os teores de PB das plantas de sorgo podem variar bastante, atingindo valores de 2,5 a 13,6\% (Vilela, 1983; Gaggiotti et al., 1992). Estas variações são atribuídas a fatores como cultivares, estádio de maturação, níveis de adubação, entre outros. Barber \& Olson (1968), citados por Malavolta \& Dantas (1987), demonstraram que doses altas de nitrogênio (N) aumentam o conteúdo de proteína nos grãos.

Verifica-se na literatura grande número de trabalhos apresentando resultados de DIVMS e, também, uma ampla faixa de variação nesses valores. Para a DIVMS do material original e silagens de sorgos forrageiro encontram-se valores de 44,7 a 63,3\% na MS (Fisher \& Burns, 1987; Gomide etal., 1987; White et al., 1991; Borges, 1995; Corrêa, 1996; Silva, 1997), para sorgos intermediários e de duplo propósito, valores de 58,1 a 66,1\% (Fisher \& Burns, 1987; Demarchi, 1993; Bernardino, 1996; Silva, 1997).

Apesar do alto potencial produtivo da cultura de sorgo e da grande disponibilidade de cultivares com características que possibilitam a sua adequação destes materiais às diferentes regiões, observa-se, muitas vezes, produção baixa e irregular. Nesse aspecto, considera-se que a fertilidade do solo e as baixas aplicações de fertilizantes sejam os principais fatores responsáveis pela baixa produtividade nas áreas destinadas à produção de silagem. Estas variações na produtividade podem também afetar as qualidades nutricionais destas forragens e, conseqüentemente, da silagem, uma vez que a qualidade da silagem depende, principalmente, das características do material original e das condições de armazenamento. Porém, segundo Oliveira (1998), informações sobre variações na qualidade do material a ser ensilado ainda são escassas no Brasil.

O sorgo pode tolerar considerável variação na fertilidade e no balanço de vários nutrientes do solo, mas a produção e a eficiência da planta são afetadas por estes fatores, podendo refletir na qualidade nutricional da forragem, uma vez que o aumento de produção é baseado em maior acúmulo de substâncias orgânicas na planta, que, por sua vez, esta relacionada com a disponibilidade de nutrientes (Loué, 1963).Objetivou-se com o presente trabalho avaliar os teores e a produtividade de MS, PB e DIVMS de cinco híbridos de sorgo cultivados sob níveis crescentes de adubação.

\section{Material e Métodos}

O experimento foi conduzido no período de 06.11.1997 a 18.02.1998, nas dependências da Central de Experimentação, Pesquisa e Extensão do Triângulo Mineiro (CEPET/UFV), no município de Capinópolis-MG, com latitude de $18^{\circ} 41^{\prime} \mathrm{S}$ e longitude de $49^{\circ} 34^{\prime} \mathrm{W}$ e altitude média de 620,20 $\mathrm{m}$. O clima é o Aw, segundo a classificação proposta por Köppen, quente e úmido, com temperatura do mês mais frio acima de $18^{\circ} \mathrm{C}(\mathrm{A})$; com estação chuvosa no verão e seca no inverno (w). Apresenta precipitações médias anuais entre 1400 e $1600 \mathrm{~mm}$. Dados relativos à temperatura e pluviosidade no período experimental são apresentados na Tabela 1.

A área experimental apresentava relevo suave ondulado e solo classificado como Latossolo Roxo eutrófico, textura argilosa, desenvolvido a partir do basalto. A área onde foi instalado o experimento foi utilizada em ensaios com soja nos anos anteriores.

Em função da análise do solo (Tabela 2) e com base na recomendação obtida pelo método do $\mathrm{Al} 3+$, $\mathrm{Ca}^{2+} \mathrm{e} \mathrm{Mg}^{2+}$ trocáveis (COMISSÃO DE FERTILIDADE DO SOLO DO ESTADO DE MINAS GERAIS, 1989), foi incorporado $400 \mathrm{~kg} / \mathrm{ha}$ de calcário (PRNT $=75 \%$ ) ao solo.

O preparo do solo consistiu de uma aração e duas gradagens para destorroamento e nivelamento do terreno, sendo a abertura dos sulcos, distribuição e incorporação do adubo e das sementes (@3 cm) efetuados manualmente. A adubação recomendada para plantio e cobertura baseou-se na análise do solo seguindo as "Recomendações Para o Uso de Corretivos e Fertilizantes em Minas Gerais" (CFSEMG, 1989), com pequena variação, devido à utilização de formulações comerciais existentes, e consistiu de $350 \mathrm{~kg} / \mathrm{ha}$ da fórmula (NPK) 06-28-08 no plantio mais $350 \mathrm{~kg} / \mathrm{ha}$ de sulfato de amônia em cobertura, dividida em duas parcelas iguais, correspondendo a uma recomendação total de $350 \mathrm{~kg}$ da fórmula (NPK) 26-28-08.

Foi utilizado um delineamento experimental em blocos casualizados, num esquema fatorial $5 \times 4$ (cinco híbridos x quatro níveis de adubação), com quatro repetições. Os híbridos utilizados foram os seguintes: 1 - AG-2002, forrageiro, porte alto, colmo suculento e população recomendada de $125.000 \mathrm{plt} / \mathrm{ha}$; 2 - AG-2005-E, duplo propósito, porte baixo, colmo seco e população recomendada de $150.000 \mathrm{plt} / \mathrm{ha}$; 3 - AG-X-202, forrageiro, porte alto, colmo seco e

R. Bras. Zootec., v.31, n.4, p.1640-1647, 2002 
Tabela 1 - Precipitação e médias das temperaturas máximas e mínimas durante o período experimental Table 1 - Rainfall and average maximum and minimum temperatures during the experimental period

\begin{tabular}{|c|c|c|c|c|}
\hline \multirow[t]{2}{*}{$\begin{array}{c}\text { Período } \\
\text { Period }\end{array}$} & \multirow[t]{2}{*}{$\begin{array}{l}\text { Semana } \\
\text { Week }\end{array}$} & \multirow[t]{2}{*}{$\begin{array}{c}\text { Precipitação }^{1}(\mathrm{~mm}) \\
\text { Temperature }\end{array}$} & \multicolumn{2}{|c|}{$\begin{array}{c}\text { Temperatura }\left({ }^{\circ} \mathrm{C}\right)^{2} \\
\text { Rainfall }\end{array}$} \\
\hline & & & $\begin{array}{l}\text { Máxima } \\
\text { Maximum }\end{array}$ & $\begin{array}{l}\text { Mínima } \\
\text { Minimum }\end{array}$ \\
\hline $06 / 11 / 97$ a $12 / 11 / 97$ & $1^{\mathrm{a}}$ & 17,0 & 34,8 & 21,9 \\
\hline $13 / 11 / 97$ a $19 / 11 / 97$ & $2^{\mathrm{a}}$ & 62,4 & 32,3 & 20,9 \\
\hline 20/11/97 a 26/11/97 & $3^{\mathrm{a}}$ & 80,8 & 32,1 & 20,9 \\
\hline 27/11/97 a 03/12/97 & $4^{\mathrm{a}}$ & 188,6 & 30,0 & 21,0 \\
\hline 04/12/97 a 10/12/97 & $5^{\mathrm{a}}$ & 67,2 & 28,9 & 20,2 \\
\hline $11 / 12 / 97$ a $17 / 12 / 97$ & $6^{\mathrm{a}}$ & 65,3 & 30,5 & 21,0 \\
\hline $18 / 12 / 97$ a $24 / 12 / 97$ & $7^{\mathrm{a}}$ & 8,7 & 30,5 & 20,9 \\
\hline $25 / 12 / 97$ a $31 / 12 / 97$ & $8^{\mathrm{a}}$ & 60,7 & 33,8 & 21,8 \\
\hline $01 / 01 / 98$ a 07/01/98 & $9^{a}$ & 12,7 & 34,5 & 21,8 \\
\hline 08/01/98 a 14/01/98 & $10^{\mathrm{a}}$ & 102,2 & 31,6 & 21,9 \\
\hline $15 / 01 / 98$ a $21 / 01 / 98$ & $11^{\mathrm{a}}$ & 40,8 & 30,8 & 20,8 \\
\hline $22 / 01 / 98$ a $28 / 01 / 98$ & $12^{\mathrm{a}}$ & 22,0 & 30,8 & 20,4 \\
\hline $29 / 01 / 98$ a 04/02/98 & $13^{\mathrm{a}}$ & 46,8 & 31,1 & 21,8 \\
\hline 05/02/98 a 11/02/98 & $14^{\mathrm{a}}$ & 62,6 & 34,2 & 21,8 \\
\hline $12 / 02 / 98$ a $18 / 02 / 98$ & $15^{\mathrm{a}}$ & 92,7 & 30,8 & 21,8 \\
\hline Total & & 930.5 & & \\
\hline
\end{tabular}

${ }^{1}$ Total do período (Total of the period).

2 Média do período (Mean of the period).

população recomendada de $125.000 \mathrm{plt} / \mathrm{ha} ; 4$ - AG-X-213, forrageiro, porte alto, colmo seco e população recomendada de $125.000 \mathrm{plt} / \mathrm{ha} ; 5$ - AG-X-215, forrageiro, porte médio/alto, colmo seco e população recomendada de $150.000 \mathrm{plt} / \mathrm{ha}$, sendo os dois primeiros comerciais e os três últimos experimentais. Os níveis de adubação utilizados no experimento foram: 1 - sem adubação de plantio e cobertura, 2 - metade da adubação recomendada para plantio e coberturas, 3 - uma vez a adubação recomendada, 4 - duas vezes a adubação recomendada.

As parcelas experimentais constituíram-se de seis fileiras, com 5 metros de comprimento, espaçadas entre si de 0,8 metros, devidamente identificadas. Em cada parcela foram utilizadas, para amostragem, as duas fileiras centrais, descontadas de 0,5 metros em cada extremidade, resultando em uma área útil de $6,4 \mathrm{~m}^{2}(4,0 \times 0,8 \times 2)$.
O plantio foi realizado em 06.11.1997 e 10 dias após a emergência foi efetuado o desbaste nas parcelas, com a finalidade de se chegar à população de plantas por hectare recomendada para cada híbrido. Aos 20 e 35 dias após a emergência, foram realizadas as adubações de cobertura nos tratamentos em que estas ocorreram. Foi realizada capina manual aos 20 dias após a emergência.

Procedeu-se à colheita quando as plantas atingiram o estádio de grãos farináceos, sendo as plantas da área útil das parcelas, cortadas a uma altura de $15 \mathrm{~cm}$ em relação ao solo e pesadas em balança tipo "dinamômetro". Do total de plantas da parcela (área útil), foram retiradas 10 plantas inteiras que foram picadas em picadeira "Nogueira modelo DPM 2", homogeneizadas, e retiradas amostras de aproximadamente $400 \mathrm{~g}$, que foram pré-secas em estufa de ventilação forçada a $65^{\circ} \mathrm{C}$, durante 72 horas. Após a

Tabela 2 - Análise do solo da área experimental

Table 2 - Soil analysis of the experimental area

\begin{tabular}{|c|c|c|c|c|c|c|c|c|c|c|}
\hline $\begin{array}{l}\text { Profundidade } \\
\text { Depth }\end{array}$ & $\mathrm{pH}$ & $\mathrm{P}$ & $\mathrm{K}$ & $\mathrm{Ca}$ & $\mathrm{Mg}$ & $\mathrm{Al}$ & $\mathrm{H}+\mathrm{Al}$ & SB & CTC & V \\
\hline $\mathrm{cm}$ & & \multicolumn{2}{|c|}{$-\mathrm{mg} / \mathrm{dm}^{3}-$} & \multicolumn{6}{|c|}{$\mathrm{cmol} / \mathrm{dm}^{3}$} & $-\%$ \\
\hline $0-20$ & 5,6 & 9,8 & 83 & 3,1 & 1,2 & 0,1 & 5,0 & 4,51 & 9,51 & 47,4 \\
\hline $20-40$ & 5,6 & 6,0 & 29 & 3,0 & 1,0 & 0,0 & 5,2 & 4,00 & 9,26 & 43,8 \\
\hline
\end{tabular}

\footnotetext{
R. Bras. Zootec., v.31, n.4, p.1640-1647, 2002
} 
retirada da estufa e permanência das amostras em condições ambientes por aproximadamente 1 hora, as mesmas foram pesadas, processadas em moínho Willey (peneira com malha de $1 \mathrm{~mm}$ ) e acondicionadas em vidros de $200 \mathrm{~mL}$ com tampa de polietileno. As amostras secas ao ar (ASA), devidamente acondicionadas, foram transportadas para as dependências do Departamento de Zootecnia da Universidade Federal de Viçosa, Viçosa-MG, onde foram determinados os teores de matéria seca (MS) e proteína bruta (PB), em aparelho micro Kjeldahl, e a digestibilidade in vitro da matéria seca (DIVMS), segundo Silva (1990).

Os dados foram interpretados por meio de análise de variância e regressão, segundo o modelo estatístico:

$$
\mathrm{Y}_{\mathrm{ijk}}=\mathrm{m}+\mathrm{B}_{\mathrm{i}}+\mathrm{H}_{\mathrm{j}}+\mathrm{A}_{\mathrm{k}}+\mathrm{HA}_{\mathrm{jk}}+\mathrm{e}_{\mathrm{ijk}}
$$

em que: $Y_{i j k}=$ observação referente à parcela do bloco i, com o híbrido j e com o nível de adubação k; $\mathrm{m}=$ média geral; $\mathrm{B}_{\mathrm{i}}=$ efeito do bloco $\mathrm{i}(\mathrm{i}=1,2,3,4)$; $\mathrm{H}_{\mathrm{j}}=$ efeito do híbrido $\mathrm{j}(\mathrm{j}=1,2,3,4,5) ; \mathrm{A}_{\mathrm{k}}=$ efeito do nível de adubação $\mathrm{k}(\mathrm{k}=1,2,3,4) ; \mathrm{HA}_{\mathrm{jk}}=$ efeito da interação híbrido x nível de adubação; e $\mathrm{e}_{\mathrm{ijk}}=$ variação aleatória (erro experimental).

As médias dos fatores qualitativos foram comparados utilizando o teste de Tukey, a 5 e $1 \%$ de probabilidade. Os modelos foram escolhidos com base na significância da regressão e na falta de ajustamento, testados pelo teste F, na significância dos coeficientes de regressão, utilizando-se o teste de Student "t", a 5 e 1\% de probabilidade, e no coeficiente de determinação. Foram determinadas correlações simples, aplicando-se o teste de Pearson a 5 e $1 \%$ de probabilidade. Como auxiliar nas análises estatísticas, utilizou-se o programa de Análises Estatística e Genética - SAEG (1995), desenvolvido pela UFV.

\section{Resultados e Discussão}

A análise de variância indicou efeito não significativo $(\mathrm{P}>0,05)$ para a interação dos fatores híbridos $\mathrm{x}$ adubação, e significativo para o fator híbrido
$(\mathrm{P}<0,01)$ sobre a produção de matéria seca total (PMS) e de proteína bruta (PPB). As médias obtidas encontram-se dispostas na Tabela 3.

De modo geral, o rendimento forrageiro dos cultivares apresentou-se relacionado com o porte da planta, conforme também verificado por Pereira (1991) e Zago (1991), que, trabalhando com híbridos forrageiros de portes alto, médio e baixo, observaram produções de MS de 18,0; 16,6; e 14,6 e 18,8; 14,6; e $10,8 \mathrm{t} / \mathrm{ha}$, respectivamente. Ese fato também foi comprovado pela alta correlação positiva $\left(0,91^{* *}\right)$, verificada neste trabalho, entre a produção MS de colmos e a produção de MS total.

A produção de MS total apresentou pequeno acréscimo linear com a elevação dos níveis de adubação ( $\mathrm{Y}=15,4719+0,3320 \# \mathrm{~A}, \mathrm{r}^{2}=0,7484$; \# $0-10 \%$ ' $t$ '), o que pode ser devido à alta produtividade alcançada pelos híbridos nos tratamentos sem adubação $(15,47 \mathrm{t} / \mathrm{ha})$, decorrente, possivelmente, das condições climáticas favoráveis e do alto nível de fertilidade do solo na área experimental. Observou-se acréscimo de 0,332 t/ha de MS, correspondente a acréscimo unitário no nível de adubação recomendado (350 kg/ha da fórmula NPK 26-28-08), correspondente a $91 \mathrm{~kg}$ de $\mathrm{N}, 98 \mathrm{~kg}$ de $\mathrm{P}_{2} \mathrm{O}_{5}$ e $28 \mathrm{~kg}$ de $\mathrm{K}_{2} \mathrm{O}$, por ha.

Os híbridos avaliados apresentaram produções satisfatórias de proteína bruta por hectare, sendo que as diferenças encontradas, provavelmente, estiveram relacionadas diretamente com suas produções de MS/ha, com exceção do AG-X202, que, com produção de $\mathrm{MS}$ estatisticamente semelhante ao AG-X213 e menor que o AG-2002 $(\mathrm{P}<0,05)$, apresentou produção de proteína bruta semelhante $(\mathrm{P}>0,05)$ ao AG-2002 e maior que ao AG-X213. Estes resultados diferem dos encontrados por Pereira (1991), que, trabalhando com híbridos de portes alto, médio e duplo propósito, registrou menor produção de PB para o híbrido de porte alto $(1,08 \mathrm{t} / \mathrm{ha})$, com

Tabela 3 - Produção de matéria seca (PMS) e de proteína bruta (PPB), em toneladas por hectare, dos híbridos avaliados Table 3 - Dry matter (DMY) and crude protein yield (CPY), t/ha, of the evaluated hybrids

\begin{tabular}{lccccc}
\hline $\begin{array}{l}\text { Produção (t/ha) } \\
\text { Yield }(t / h a)\end{array}$ & \multicolumn{3}{c}{$\begin{array}{c}\text { Híbridos } \\
\text { Hybrids }\end{array}$} \\
\cline { 2 - 6 } & AG-2002 & AG-2005E & AG-X202 & AG-X213 & AG-X215 \\
\hline PMS & $18,71^{\mathrm{a}}$ & $12,54^{\mathrm{d}}$ & $16,21^{\mathrm{b}}$ & $16,75^{\mathrm{b}}$ & $14,60^{\mathrm{c}}$ \\
PPB & $1,19^{\mathrm{a}}$ & $0,93^{\mathrm{b}}$ & $1,12^{\mathrm{a}}$ & $1,01^{\mathrm{b}}$ & $0,99^{\mathrm{b}}$ \\
\hline
\end{tabular}

Médias, na linha, seguidas por letras distintas, diferem pelo teste Tukey $(\mathrm{P}<0,05)$.

Means, within a row, followed by different letters, differ $(P<.05)$ by Tukey test.

R. Bras. Zootec., v.31, n.4, p.1640-1647, 2002 
uma produção de MS de 18,0 t/ha, enquanto o híbrido de portes médio e duplo propósito produziram 1,34 e $1,25 \mathrm{t} / \mathrm{ha}$ de $\mathrm{PB}$, para produções de MS de 16,6 e $14,6 \mathrm{t} / \mathrm{ha}$, respectivamente.

A interação dos fatores híbrido $\mathrm{x}$ adubação para a produção de proteína bruta não apresentou diferença $(\mathrm{P}>0,05)$, enquanto o fator adubação foi significativo $(\mathrm{P}<0,01)$ (Figura 1).

Estimou-se a produção de proteína bruta máxima em $1,1388 \mathrm{t} / \mathrm{ha}$, para o nível de adubação igual a 1,727 vezes a adubação recomendada $(604,4 \mathrm{~kg} / \mathrm{ha}$ de 26-28-08).

O estudo da análise de variância dos teores de proteína bruta $(\mathrm{PB})$ apresentaram diferença $(\mathrm{P}<0,01)$ para os fatores híbrido e adubação e para a interação híbrido x adubação.

Os resultados registrados para os teores médios de $\mathrm{PB}$ dos híbridos em cada nível de adubação encontram-se dispostos na Tabela 4 e as equações de regressão para cada híbrido, em função dos níveis de adubação, são apresentados na Tabela 5.

Os híbridos apresentaram tendências de respostas diferenciadas com o aumento dos níveis de adubação, entretanto observa-se maior teor de $\mathrm{PB}$ em todos os níveis de adubação para o AG-2005E e menores para o AG-X213. Segundo Zago (1991), os híbridos de portes médio ou baixo têm apresentado teores de PB superiores aos híbridos de porte alto, em função de maior participação de folhas e panículas na massa ensilada. Nesse aspecto, cabe ressaltar o híbrido AG-X202, de porte alto, que apresentou, exceto para o nível de 0,5 adubação

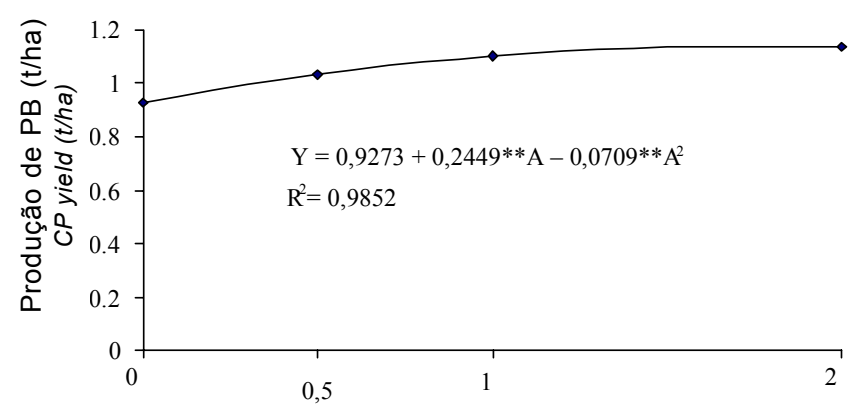

Níveis de adubação recomendada (vezes) Fertilizer levels

Figura 1 - Estimativas das produções de proteína bruta (t/ha), em função dos níveis de adubação.

Figure 1 - Estimates of the crude protein (t/ha), according to the fertilizer levels. recomendada, teores de $\mathrm{PB}$ estatisticamente semelhante ao AG-2005E (duplo propósito).

O híbrido AG-X202 apresentou resposta linear positiva ao aumento dos níveis de adubação, com aumento de $0,7314 \%$ no teor de PB a cada aumento unitário do nível de adubação. Os outros híbridos apresentaram respostas quadráticas distintas, em função dos níveis de adubação, estimando-se teores máximos de $\mathrm{PB}$ de $6,66 \%$ (AG-2002), 8,06\% (AG-2005-E), 6,44\% (AGX213) e 7,25\% (AG-X215) para níveis de adubação de 1,202; 1,846; 1,494; e 1,659 vezes a recomendação, respectivamente.

Santos (1996), trabalhando com cultivares de sorgo de porte alto e tratamentos sem adubação, com $80 \mathrm{~kg}$ de N, $50 \mathrm{~kg}$ de $\mathrm{P}_{2} \mathrm{O}_{5}$ e $70 \mathrm{~kg}$ de $\mathrm{K}_{2} \mathrm{O}$ por hectare e $150 \mathrm{~kg}$ de N, $130 \mathrm{~kg}$ de $\mathrm{P}_{2} \mathrm{O}_{5}$ e $220 \mathrm{~kg}$ de $\mathrm{K}_{2} \mathrm{O}$ por hectare, registrou elevação nos teores médios de $\mathrm{PB}$ de 3,$02 ; 4,02 ;$ e $5,28 \%$, respectivamente, sendo estes inferiores aos obtidos no presente experimento.

A interação entre os fatores híbrido $\mathrm{x}$ adubação não apresentou efeitos $(\mathrm{P}>0,05)$ quanto à digestibilidade in vitro da matéria seca (DIVMS) e produção de matéria seca digestível (PMSD), enquanto os fatores isolados, híbrido e adubação, apresentaram efeitos significativos pelo teste $\mathrm{F}$ a 1 e $5 \%$, respectivamente.

Os valores relativos às médias da digestibilidade in vitro da MS (DIVMS) e da produção de matéria seca digestível por hectare (PMSD) encontram-se na Tabela 6.

A digestibilidade in vitro da matéria seca mos-

Tabela 4 - Teores médios de proteína bruta (PB) dos híbridos em porcentagem na MS, nos níveis de adubação testados

Table 4 - Average crude protein (CP) contents of the hybrids, $\% D M$, in the fertilizer levels

\begin{tabular}{lclcc}
\hline $\begin{array}{l}\text { Híbrido } \\
\text { Hybrids }\end{array}$ & \multicolumn{4}{c}{$\begin{array}{c}\text { Níveis de adubação recomendado (vezes) } \\
\text { Fertilizer levels }\end{array}$} \\
\hline & 0 & 0,5 & 1 & 2 \\
\hline AG-2002 & $6,03^{\mathrm{a}}$ & $6,48^{\mathrm{bc}}$ & $6,62^{\mathrm{cd}}$ & $6,39^{\mathrm{c}}$ \\
AG-2005E & $6,45^{\mathrm{a}}$ & $7,44^{\mathrm{a}}$ & $7,59^{\mathrm{a}}$ & $8,08^{\mathrm{a}}$ \\
AG-X202 & $6,31^{\mathrm{a}}$ & $6,45^{\mathrm{bc}}$ & $7,19^{\mathrm{ab}}$ & $7,69^{\mathrm{ab}}$ \\
AG-X213 & $5,36^{\mathrm{b}}$ & $6,08^{\mathrm{c}}$ & $6,25^{\mathrm{d}}$ & $6,33^{\mathrm{c}}$ \\
AG-X215 & $6,11^{\mathrm{a}}$ & $6,74^{\mathrm{b}}$ & $7,04^{\mathrm{c}}$ & $7,21^{\mathrm{b}}$ \\
\hline
\end{tabular}

Médias, nas colunas, seguidas por letras minúsculas distintas, diferem pelo teste Tukey $(P<0,05)$.

Means, within a column, followed by different small letters, differ $(P<.05)$ by Tukey test.

R. Bras. Zootec., v.31, n.4, p.1640-1647, 2002 
Tabela 5 - Equações de regressão estimadas dos teores de proteína bruta (\%MS) e níveis de adubação (A) dos híbridos avaliados e coeficientes de determinação

Table 5 - Estimates regression equations of crude protein contents (\% DM) and fertilizer levels (A) of the evaluated hybrids and coefficients of determination

\begin{tabular}{lcr}
\hline $\begin{array}{l}\text { Híbrido } \\
\text { Hybrid }\end{array}$ & $\begin{array}{c}\text { Equação de regressão } \\
\text { Regression equations }\end{array}$ & $\mathrm{R}^{2} / \mathrm{r}^{2}$ \\
\hline AG-2002 & $\mathrm{Y}=6,0402+1,0360 * * \mathrm{~A}-0,4308 * * \mathrm{~A}^{2}$ & 0,9916 \\
AG-2005E & $\mathrm{Y}=6,5204+1,6735 * \mathrm{~A}-0,4533 * * \mathrm{~A}^{2}$ & 0,9527 \\
AG-X202 & $\mathrm{Y}=6,2717+0,7314 * * \mathrm{~A}$ & 0,9417 \\
AG-X213 & $\mathrm{Y}=5,4031+1,3852 * * \mathrm{~A}-0,4637 * \mathrm{~A}^{2}$ & 0,9703 \\
AG-X215 & $\mathrm{Y}=6,1254+1,3591 * * \mathrm{~A}-0,4095 * * \mathrm{~A}^{2}$ & 0,9955 \\
\hline
\end{tabular}

** Significativo $(P<0,01)$ pelo teste ' $t$ '.

** Significant $(P<.01)$ by $t$ test.

Tabela 6 - Médias para a digestibilidade in vitro da matéria seca (DIVMS), em porcentagem, e da produção de matéria seca digestível (PMSD), em toneladas por hectare

Table 6 - Means for the dry matter digestibility (IVDMD), \%, and of the digestible dry matter yield (DDMY), t/ha

\begin{tabular}{lccccc}
\hline & \multicolumn{5}{c}{$\begin{array}{c}\text { Híbridos } \\
\text { Hybrids }\end{array}$} \\
\cline { 2 - 6 } & AG-2002 & AG-2005E & AG-X202 & AG-X213 & AG-X215 \\
\hline DIVMS(\%) & $54,56^{\mathrm{b}}$ & $61,69^{\mathrm{a}}$ & $54,61^{\mathrm{b}}$ & $52,97^{\mathrm{b}}$ & $53,79^{\mathrm{b}}$ \\
PMSD (t/ha) & $10,22^{\mathrm{a}}$ & $7,75^{\mathrm{c}}$ & $8,85^{\mathrm{b}}$ & $8,88^{\mathrm{b}}$ & $7,85^{\mathrm{c}}$ \\
\hline
\end{tabular}

Médias, na linha, seguidas por letras distintas, diferem pelo teste de Tukey $(P<0,05)$.

Means, within a row, followed by different letters, differ $(P<.05)$ by Tukey test.

trou-se correlacionada positivamente com o nível de adubação, conforme se verifica na Figura 2. Estimou-se aumento de $1,13 \%$ na DIVMS, para cada variação unitária no nível de adubação.

A produção de matéria seca digestível é função da produção de matéria seca da forrageira e de sua digestibilidade. Entre os híbridos avaliados, verificou-se maior efeito da produção que da digestibilidade sobre a produção de matéria seca digestível. Verificou-se correlação linear entre a produção de MS/ha e a produção de MS digestível por hectare de $0,91^{* *}$ e correlação linear não significativa com a DIVMS. Cabe ressaltar que o AG-2005E produziu aproximadamente duas toneladas a menos de MS por hectare que o AG-X215, entretanto apresentou produção de MS digestível igual, devido à sua maior DIVMS.

A produção de matéria seca digestível por hectare variou diretamente com os níveis de adubação utilizados (Figura 3). Isso se deve, provavelmente, ao aumento verificadona produção de MS, bem comona digestibilidade da forragem com o aumento da adubação.

\section{Conclusões}

Os híbridos avaliados apresentam teores satisfatórios de proteína bruta e digestibilidade in vitro da matéria seca, e alta produtividade média por hectare de matéria seca, de matéria seca digestível e de proteína bruta, ressalvando as altas produções nas parcelas sem adubação, em função da fertilidade do solo e condições climáticas favoráveis.

O aumento nos níveis de adubação ocasiona respostas diferenciadas quanto aos teores de proteína bruta, predominando respostas quadráticas, determinando o comportamento quadrático da produção de proteína bruta por hectare. A produção de matéria seca, a digestibilidade in vitro da matéria seca e a produção de matéria seca digestível apresentaram relações lineares diretas, em função dos níveis de adubação.

R. Bras. Zootec., v.31, n.4, p.1640-1647, 2002 


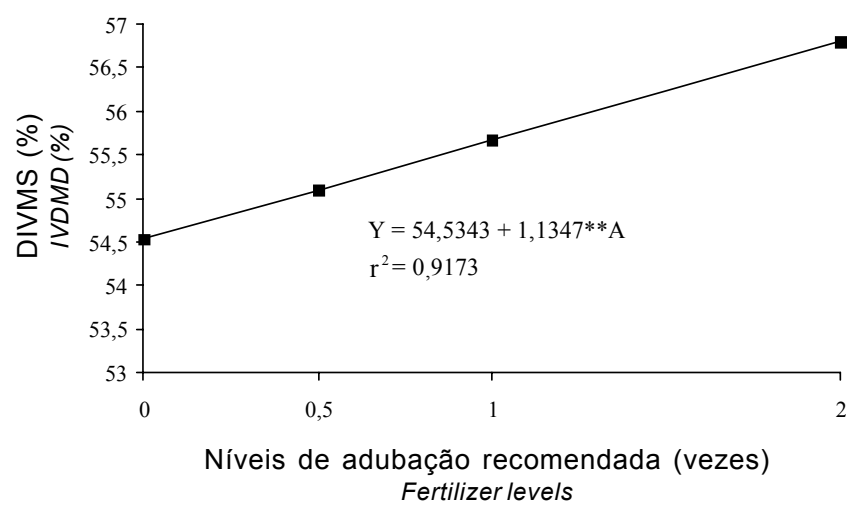

Figura 2 - Estimativas da digestibilidade in vitro da matéria seca (DIVMS), em função dos níveis de adubação (A) dos híbridos avaliados.

Figure 2 - Estimates of dry matter in vitro digestibility matter (DMIVD), according to the fertilizer levels $(A)$ of the evaluated hybrids.

\section{Literatura Citada}

BERNARDINO, M.L.A. Avaliação nutricional de silagens de híbridos de sorgo (Sorghum bicolor (L.) Moench) de porte médio com diferentes teores de taninos e suculeência no colmo. Belo Horizonte: Universidade Federal de Minas Gerais, 1996. 87p. Dissertação (Mestrado em Zootecnia) - Universidade Federal de Minas Gerais, 1996.

BORGES, A.L.C.C. Qualidade de silgens de híbridos de sorgo de porte alto, com diferentes teores de tanino e de umidade no colmo, e seus padrões de fermentação. Belo Horizonte: Universidade Federal de Minas Gerais, 1995. 104p. Dissertação (Mestrado em Zootecnia) - Universidade Federal de Minas Gerais, 1995.

COMISSÃO DE FERTILIDADE DO SOLO DO ESTADO DE MINAS GERAIS. Recomendações para uso de corretivos e fertilizantes em Minas Gerais; 4 Aproximação. Lavras: 1989. $159 \mathrm{p}$.

CORREAA, C.E.S.; RODRIGUES, J.A.S.; GONÇALVES, L.C. Determinação da produção de matéria seca e das proporções de colmo, folha e panícula de treze híbridos de sorgo. In: REUNIÃO ANUAL DA SOCIEDADE BRASILEIRA DE ZOOTECNIA, 33., 1996, Fortaleza. Anais... Fortaleza: Sociedade Brasileira de Zootecnia, 1996. p.374-376.

CUMMINS, D.G. Yield and quality changes with maturity of silage type sorghum fodder. Agronomy Journal, v.73, n.3, p.988-990, 1981.

DEMARCHI, J.J.A.A. Produção, valor nutritivo e características fermentativas de silagem de sorgo (Sorghum vulgare Pers.) em cinco estádios de maturação. Piracicaba: Escola Superior de Agricultura "Luiz de Queiroz, 1993.94p. Dissertação (Mestrado em Zootecnia) - Escola Superior de Agricultura "Luiz de Queiroz", 1993.

FISHER, D.S.; BURNS, J.C. Quality analysis of summer-annual forages. Agronomy Journal, v.79, n.2, p.236-253, 1987.

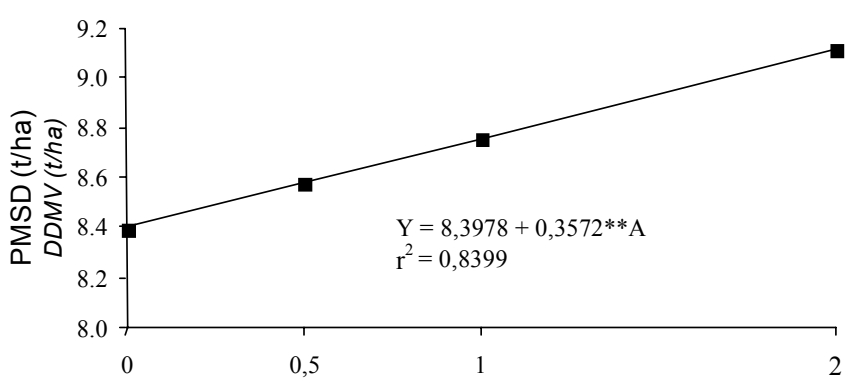

Níveis de adubação recomendada (vezes) Fertilizer levels

Figura 3 - Estimativas das produções de matéria seca digestível (PMSD), em função dos níveis de adubação $(\mathrm{A})$.

Figure 3 - Estimates of digestible dry matter yield (DDMY), according to the fertilizer levels

GAGGIOTE, M.C.; ROMERO, L.A.; BRUNO, O.A. et al Cultivares del sorgo forrajero a la silaje. II características fermentativas e nutritivas de los silajes. Revista Argentina Producion Animal, v.12, n.2, p.163-167, 1992

GOMIDE, J.A.; ZAGO, C.P.; CRUZ, M.E. Milho e sorgo em cultivos puros ou consorciados com soja, para produção de silagem. Revista Brasileira Zootecnia, v.16, n.4, p.308-317, 1987.

LOUÉ, A. Estudo comparativo das exigências minerais de algumas variedades de milho híbrido. Fertilité, v.20, p22-32, 1963.

MALAVOLTA, E.; DANTAS, J.P. Nutrição e adubação de milho. In: PATERNIANE, E., VIEGAS, G.P. (Eds.) Melhoramento e produção de milho. 2.ed. Campinas: Fundação Cargill, 1987. v.2, p.539-593.

OLIVEIRA, J.S. Produção e utilização de silagem de milho e sorgo. Juiz de Fora: EMBRAPA- CNPGL, 1998. 34p. (Circular Técnica, 47).

PEREIRA, O.G. Produtividade do milho (Zea may L.), do sorgo (Sorghum bicolor (L.) Moench), da aveia (Avena Sativa), do milheto (Pennisetum americanum L.) e do híbrido ( $S$. bicolor $\mathrm{x} S$. sudanense) e respectivos valores nutritivos sob a forma de silagem e verde picado. Viçosa, MG: Universidade Federal de Viçosa, 1991. 86p. Dissertação (Mestrado em Zootecnia) - Universidade Federal de Viçosa, 1991.

PEREIRA, O.G., OBEID, J.A., GOMIDE, J.A. et al. Produtividade de uma variedade de milho (Zea mays L.) e de três variedades de sorgo (Sorghum bicolor (L.) Moench) e o valor nutritivo de suas silagens. Revista Brasileira de Zootecnia, v.22, n.1, p.31-38, 1993 .

SANTOS, L.A. Silagens de milho e sorgo: Rendimento, qualidade e custo operacional. Pelotas, RS: Universidade Federal de Pelotas, 1996. 131p. Dissertação (Mestrado em Produção Vegetal) - Universidade Federal de Pelotas, 1996.

SILVA, D.J. Análise de alimentos (métodos químicos e biológicos). Viçosa, MG: Universidade Federal de Viçosa, 1990. 166p.

SILVA, F.S. Qualidade de silagens de híbridos de sorgo (Sorghum biocolor (L.) Moench) de portes baixo, médio

R. Bras. Zootec., v.31, n.4, p.1640-1647, 2002 
e alto com diferentes proporções de colmo + folhas/ panícula. Belo Horizonte: Universidade Federal de Minas Gerais, 1997. 94p. Dissertação (Mestrado em Zootecnia) Universidade Federal de Minas Gerais, 1997.

UNIVERSIDADE FEDERAL DE VIÇOSA - UFV. S.A.E.G. (Sistema da Análises Estatística e Genéticas). Viçosa, MG, 1995. (Versão 5.0).

VALENTE, J.O.; SILVA, J.F.C.; GOMIDE, J.A. Estudo de duas variedades de milho (Zea mays L.) e de quatro variedades de sorgo (Sorghum bicolor (L.) Moench), para silagem. 2. Valor nutritivo e produção de silagens. Revista da Sociedade Brasileira de Zootecnia, v.13, n.1, p.74-81, 1984.

VALENTE, J.O. Introdução. In: EMBRAPA. Centro Nacional de Pesquisa de Milho e Sorgo (Sete Lagoas, MG). Manejo cultural do sorgo para forragem. Sete Lagoas: EMBRAPACNPMS, 1992. p.5-7. (Circular técnica, 17)

VILELA, D. Silagem. Informe Agropecuário, v.9, n.108, p.17-27, 1983.
WHITE, J.S., BOLSEN, K.K., POSLER, G. Forage sorghum dry matter disappearance as influenced by plant part proportion. Animal Feed Science and Technology, v.33, n.3, p.313322, 1991.

ZAGO, C.P. Cultura de sorgo para produção de silagem de alto valor nutritivo. In: SIMPOSIO SOBRE NUTRIÇÃO DE BOVINOS, 4., 1991, Piracicaba. Anais... Piracicaba: Fundação de Estudos Agrários “Luís de Queiroz”, 1991. p.169-217.

Recebido em: 13/12/01

Aceito em: 08/05/02 